\title{
Variation of Adhesive Strength in Single Lap Joint (SLJ) with Surface Irregularities
}

\author{
Aditya V. Natu*, Ankit R. Sharma*, Nitinkumar R. Anekar \\ Department of Mechanical Engineering, MIT-COE, Pune, India \\ *Corresponding author: adityanatu97@gmail.com, ankit4444.as@gmail.com.com \\ Received January 17, 2019; Revised March 20, 2019; Accepted April 14, 2019
}

\begin{abstract}
Single Lap Joints are used extensively in the aerospace industry due to their lower weight and absence of stress concentration due to drilled holes. However, their lesser strength remains an important limitation. Different modes of failures have been reviewed in this article. The bond strength of a single lap joint can be varied by varying its overlap length, while, the strength does not strictly increase with increasing bonding length. Rather, it increases up to an optimum value and decreases further. This optimum value was obtained, which is found to be in agreement with previous studies in this regard. The surfaces of the bonded aluminum plates were modified by generating notch shaped pattern on bonding area. Due to notch pattern of bonding, the bond strength increases up to $75^{\circ}$ notch angle and then decreases with further increase in the notch angle. The experimental results of bonded joints without notch also were obtained by software analysis. Maximum strength of joint length reached at optimum length and optimum notched surface pattern.
\end{abstract}

Keywords: single- lap joint, adhesive, surface irregularities (Notch), epoxy resin, aluminum, bond strength, FEA, UTM Testing, adhesive joint analysis, bond strength

Cite This Article: Aditya V. Natu, Ankit R. Sharma, and Nitinkumar R. Anekar, "Variation of Adhesive Strength in Single Lap Joint (SLJ) with Surface Irregularities." American Journal of Mechanical Engineering, vol. 7, no. 2 (2019): 61-67. doi: 10.12691/ajme-7-2-2.

\section{Introduction}

Industries involved with aircraft and automobile construction are the major users of adhesive bonding of metals. Adhesive bonded assemblies may comprise over 50 percent of the total area of a modern airplane due to time and cost saving, high corrosion and fatigue resistance [1]. Now-a-days, many structures are manufactured as single parts, and then connected through adhesive joints. The commonly used methods for joining composite parts are either through mechanical fastening or bonding. Mechanical fasteners including bolts, rivets, and pins have been commonly used for several decades. The key problem with these causes high stress concentrations around the fastener holes, and the joint can be brought to failure at far lower stress levels than expected. Hence adhesive bonding is used due to its larger bond area to distribute loads and eliminate stress concentration as well as keeping structure integrity. It also has other benefits like improved stiffness, rigidity, impact behavior and energy absorption, less vibration and sound deadening. Adhesives resist the separation loads up to a particular point and avoid permanent damage to the material. It is also affected by factors including the geometry and the material properties of the adherends and the adhesive. If the load is not very high adhesive joint also become very useful in joining metallic or non-metallic dissimilar materials. No special device is needed. But the disadvantage of this joint is that the joint gets weakened by moisture or heat, so some adhesives need meticulous surface preparation. In an adhesive joint, adhesive are applied between two plates (known as adherends). Adhesive bonding of metal-to-metal accounts for less than $2 \%$ of the total metal joining applications [2].

The commonly used adhesive joint configuration in load carrying structures is the single lap joint (SLJ). Despite its apparent simplicity, the stress and strain states and the failure mechanisms in SLJs are complex. The structured way of analyzing the stress-strain responses as well as the failure process of adhesive joints are synthesized and reviewed based on material properties obtained from experimental tests. Different failure modes associated with single lap joint are shown in Figure 1.

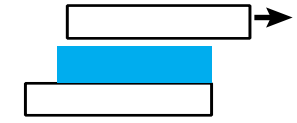

(a)

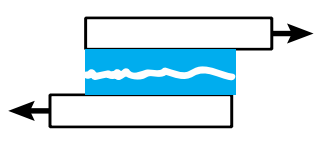

(c)

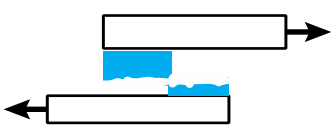

(b)

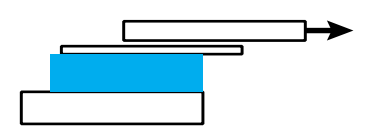

(d)
Figure 1. Adhesive Failure Modes (a) Adhesion Failure (b) Adhesion/Cohesion Failure (c) Cohesion Failure and (d) Substrate Failure 
The failure load increases with overlap length and adhesive thickness. Material properties and geometry size were investigated significantly to see effect on the joint strength and failure modes. On account of the effect of factors mentioned above, A. Ghumatkar [2] focused on improving the strength of the joints. The joint strength in- creased by modifying the shape of the joint and adding chamfer and fillets. The quality of the bonded joints depends highly on the manufacturing process. Their study shows the effects on bond strength after varying roughness using emery paper. Surface preparation is one of the important parameters which is directly related to the quality of the bonded joint. Lucas da Silva [3] found that the mechanical response and failure behavior of adhesive bonded joints are strongly dependent on the geometry and material properties of the constituents. A. B. Ghani [4] focused on adhesive failure modes. Failure in bonded joints can occur in three distinctly different modes, namely failure in the adhesive (cohesive failure), constituent adherends and interfaces between the adhesive and the adherend materials. Yasmina Boutar [5] presented surface treatment on the overlap region and curing conditions such as pressure and temperature. One parameter that influences the strength of the adhesive joint, and therefore can be altered to obtain maximum shear strength, is the surface geometry.

\section{Problem Statement}

The strength of a single lap joint changes with a change in overlap length and surface roughness. However, the change is not a monotonous rise or fall in strength. Instead, the strength increases up to a maximum value and decreases thereafter. Therefore, we have an optimum value of these parameters where the highest adhesive strength is obtained. The problem statement for this article is to create small v-shaped notches on the overlapping region of the adherends and vary the angle of the notch (as shown in Figure 3). The effects if these notches can be studied by simulation using an FEA Package. An optimum value if the notch angle which provides the greatest enhancement of adhesive strength can be obtained.

\section{Methodology}

The geometry in failure analysis of bonded joints are discussed in the following points.

\subsection{Geometry}

The surface at contact with joint of the Aluminum plates was modified by generating patterns. To check strength of joint, triangular notch pattern were taken on both adhered plate at contact with adhesive.

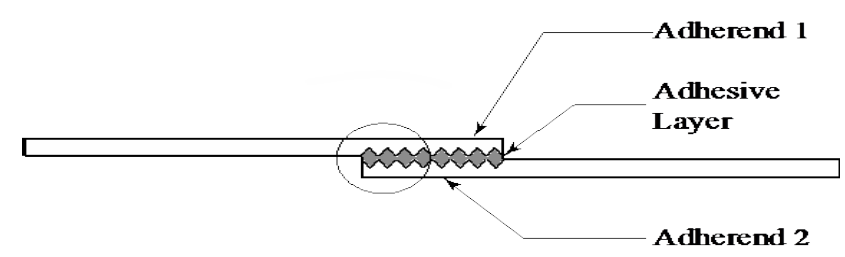

Figure 2. Single Lap Joint with Pattern
The pattern on adhered plate is shown in Figure 2. Some parameters were considered during pattern preparation as inclination angle $\left(\Phi=75^{\circ}\right)$ of triangular notch, depth of triangular notch $(d=0.5 \mathrm{~mm})$, plate thickness $(\mathrm{t}=6 \mathrm{~mm})$ and distance. These parameters were obtained after a number of software analysis trials on bonded joints. Detailed view of pattern notch with parameter is shown in Figure 3.

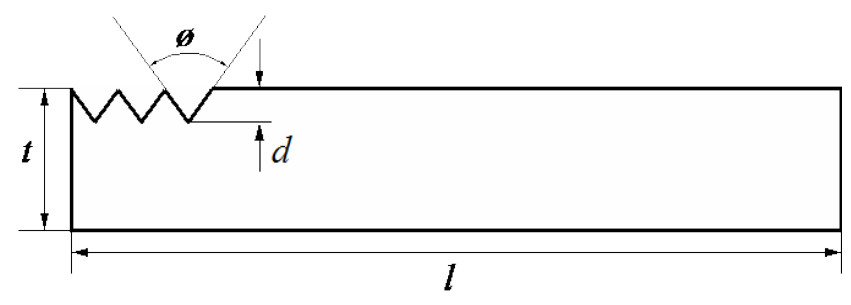

Figure 3. Pattern with a Triangular Notch

\subsection{Failure Analysis}

In Failure Analysis, area of overlap and the length of overlap obtained from Equation (1).

$$
A_{p}=L_{p} \times(\text { Width of Bond }) .
$$

Then, the shear stress is related to shear force (V) as given below:

$$
\mathrm{F}=\tau \times \mathrm{A}_{\mathrm{p}}
$$

The shear strength was calculated from experimental evaluation of shear force. After application of load the single lap joint undergoes certain deformation. The distribution of tensile stress and shear stress along the $x$-direction and the deformed shape is shown in Figure 4.

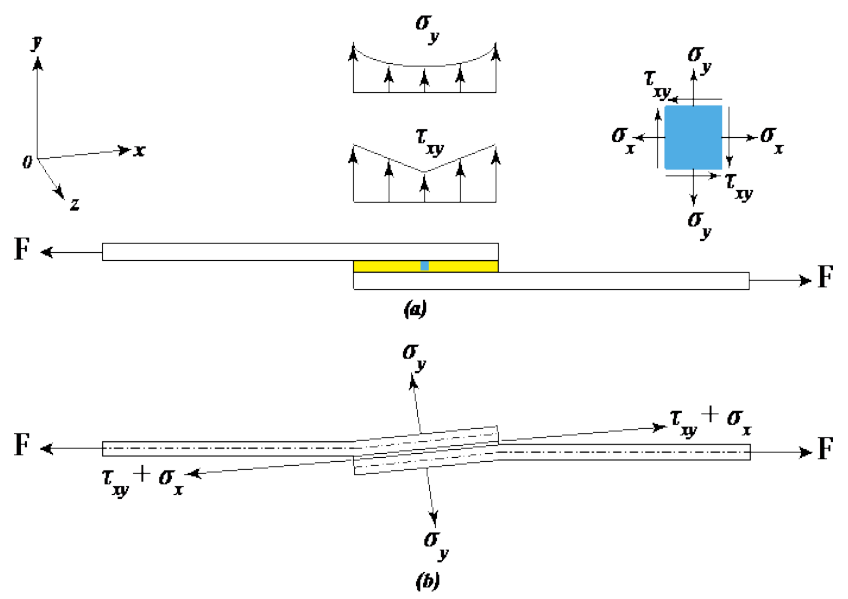

Figure 4. Deformation of the single lap joint after application of loads(a) undeformed shape (b) deformed shape

NPL Design Manual [8] suggests the Maximum Principle Stress theory for adhesive joints, as it is the most successful theory for brittle materials. According to this theory,

$$
\sigma_{1}=\frac{\sigma_{x}-\sigma_{y}}{2}+\frac{1}{2} \sqrt{\left(\sigma_{x}-\sigma_{y}\right)^{2}+4 \tau_{x y}^{2}} .
$$

Condition for failure checking of adhesive joint are given as, if Max. Principle stress $\left(\sigma_{1}\right)$ is greater than failure stresses $\left(S_{y t}\right.$ or $\left.S_{u t}\right)$, then the joint will fail and if $\sigma_{1}$ 
is positive, then take $S_{y t}$ or $S_{u t}$, else $\sigma_{1}$ is negative, then $S_{y c}$ or $S_{u c . .}$ Accurate criteria for polymeric adhesives considered as below: Let $\sigma_{1}$ be the maximum normal stress and $\tau$ be the maximum shear stress. Here, factor of safety $\left(f_{s}\right)>1$. Max. Principle stress $\left(\sigma_{1}\right)$ is less than or equal to Permissible stress $\left(\sigma_{p e r}\right)$ where

$$
\text { Permissible Stress }=\frac{\text { Failure Stress }}{\text { Factor of Safety }}=\frac{\mathrm{S}_{\mathrm{yt}}}{\mathrm{f}_{\mathrm{s}}} \text { or } \frac{\mathrm{S}_{\mathrm{ut}}}{\mathrm{f}_{\mathrm{s}}} \text {. }
$$

Then,

$$
\sigma_{1} \leq \frac{S_{y t}}{f_{s}} \text { or } \frac{S_{u t}}{f_{s}}
$$

The values are given to software analysis for identifying failure of joints.

\section{Geometric Parameters of Analysis}

The geometric parameters of analysis of single lap joint are discussed as below,

\subsection{Bond-line Thickness}

Venkateshwara Rao [4] studied the effect of adhesive thickness on bonded joints using analytical models, finite element methods (FEMs) and experimental methods. For SLJs, it was shown that strength of SLJ decreases as the adhesive thickness increases. The reduction in joint strength was attributed to the fact because thicker bondline contain more defects such as voids, micro-cracks and higher interface stresses. Also, numerical results supported that the ductility of the adhesive increases as the adhesive thickness is increased. Moreover, there is no any generalized trend between strength and adhesive thickness and these mixed behaviour may be attributed to various factors such as the type of loading (mode I, mode II, or mixed), the adherend behaviour (elastic or plastic), type of adhesive (ductile or brittle), geometry of joints etc. which can modify the behaviour of bonded joints as their thickness is varied In summary, it is important to consider the adhesive properties, geometrical parameters and also loading type for optimizing the adhesive thickness.

\subsection{Joint Configuration}

The joint configuration that produces local stress concentrations, high peel stresses and interfacial stresses. These should be avoided because it leads to premature failure of joints. A wide variety of joint configurations are used in practices and most of them. All the geometrical parameters (i.e. adherend thickness, width, adhesive thickness etc.) have an effect on bonded joints performance. Therefore, it's necessary to optimize these parameters for maximum strength of joints provided its feasibility. Here joint design is considered such that bond area equally shares the stress in optimum length.

\subsection{Overlap Length}

Increasing the overlap length increases the joint strength up to a certain limit. However, the increment rate depends on the adhesive material, adherend material and the type of loading. In a study performed by Balkova et al. [11], to test the shear strength of adhesively bonded single lap joints, four overlap lengths (10, 20, 30 and $40 \mathrm{~mm})$ were tested and it was found that with increase in overlap length, the failure load increased parabolically. Actually, the ideal overlap length depends on the pairs of adhesive-adherends. Here first optimum overlap length is found which is optimum.

\subsection{Material Properties}

Most of the industries are demanding new adhesive materials with advanced properties which should satisfy the required conditions for a specific application. The selection of adhesive materials for a specific application depend upon adherend type to be bonded, curing temperature, expected environmental condition during service, type of load and cost.The primary reason for epoxy's popularity is its superb mechanical strength, light weighting, sound and vibration dampening, resistance to chemicals, corrosion and heat. Welding is often the only alternative. Epoxy is nearly always cheaper and faster than welding. The epoxy resin is used as adhesive and AluminumT6061 is used as adherend in current study. The material properties of adherend plate and adhesive are given in Table 1.

Table 1. Properties of Materials

\begin{tabular}{|l|c|c|}
\hline Property & $\begin{array}{c}\text { Adherend } \\
\text { (Aluminum T6061) }\end{array}$ & $\begin{array}{c}\text { Adhesive } \\
\text { (Epoxy Resin) }\end{array}$ \\
\hline$E(\mathrm{GPa})$ & $72^{*}$ & 3.790 \\
\hline$v$ & $0.35^{\#}$ & 0.35 \\
\hline$\rho\left(\mathrm{kg} \mathrm{m}^{-3}\right)$ & 2770 & 0.00113 \\
\hline$K(\mathrm{~Pa})$ & $6.69 \times 10^{10}$ & $4.2 \times 10^{9}$ \\
\hline$G(\mathrm{MPa})$ & $2.6692 \times 10^{4}$ & 1400 \\
\hline$S_{t y}(\mathrm{MPa})$ & $2.8 \times 10^{4^{*}}$ & 54.6 \\
\hline
\end{tabular}

* From Figure 5, \# from reference [3].

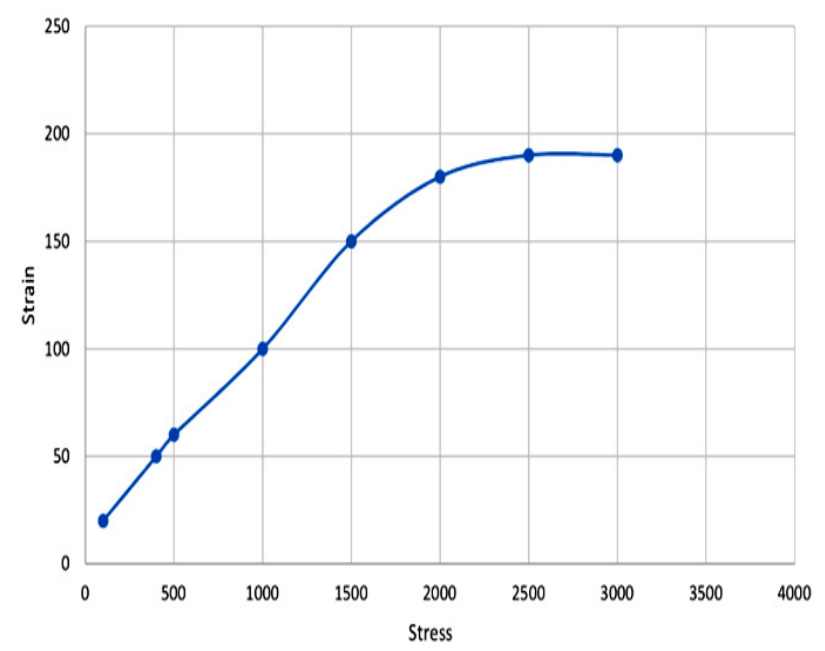

Figure 5. Stress- Strain Plot of Aluminum T6061

Special attention should be taken for the selection of the adherend materials, as different materials behave differently and affect the final performance of the joints. A significant difference in strength was observed, in the case 
of joints bonded with the different adherend material, under the same conditions. Aluminium is used as adherend in this research article. The Stress-Strain plot of Aluminium T606 is given in Figure 5. The plots are obtained from UTM (Universal Testing Machine) at Praj Lab, Pune at $25^{\circ} \mathrm{C}$ at $5 \mathrm{~mm} / \mathrm{min}$.

\section{Analysis of Adhesively Bonded Joints}

Analyses of adhesively bonded joints are carried out by using analytical methods and finite element methods (FEM). The Analytical methods are easy, fast and with high accuracy, but certain assumptions are necessary for complex joints and that might limit the accuracy of the results. On the other hand, the FEM has the capability to analyse complex geometries, complex material model without introducing any assumption but computing time is the only constraint

\subsection{Element}

Hazimeh [7] described a process of building and testing of numerical models of adhesive bonds to study the dynamics of the joints. The adhesive layer was built up using 4 elements through its thickness, resulting in the smallest element dimension equal to $0.025 \mathrm{~mm}$. The bond edges were refined to the mesh size of $5 \times 25 \times 100$ micrometres. To obtain accurate results for the analysis of adhesive joints, the models are usually meshed in extremely fine manner, using volume (brick) elements for the discretization of adhesive and adherends. This method allows for thorough examination of the joint stress pattern and strength. The finite element mesh is generated using a three-dimensional brick element 'SOLID45' as shown in Figure $6[6,13]$

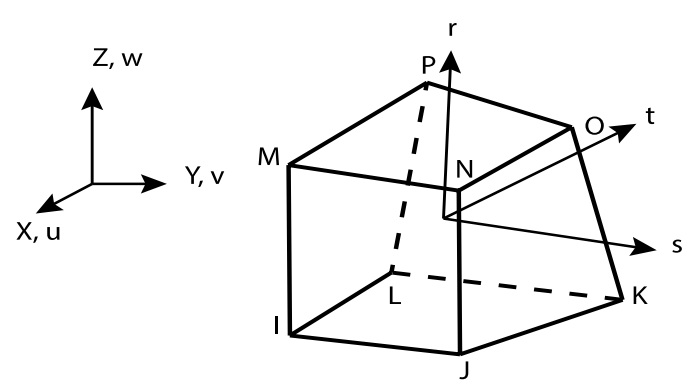

Figure 6. Element SOLID 45

This element is a structural solid element based on three-dimensional elasticity theory. It is used to model thick orthotropic solids. The element is defined by 8 nodes having three degrees of freedom per node as translations in the nodal $\mathrm{x}, \mathrm{y}$, and $\mathrm{z}$ directions.

\subsection{Boundary Conditions and Loading}

Various boundary conditions and loading conditions can be applied for analysis of single lap joint. These are given as below,

\section{Case 1: Optimum Overlap Length}

For the case 1, analysis was done for optimum overlap length. The overlap length is the length where adhesive is applied between the two plates.

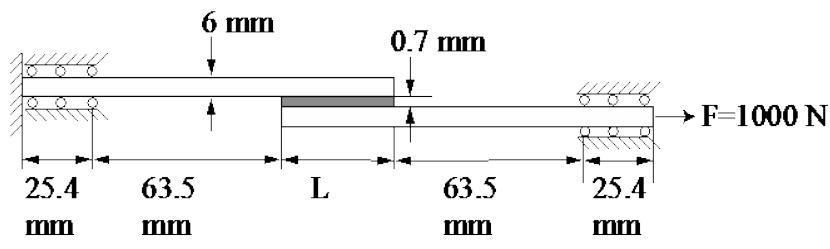

Figure 7. Optimum Overlap Length for Single Lap Joint without notches

Boundary conditions for this case are as fixed support on one end and frictionless support of $25.4 \mathrm{~mm}$ length on both ends of plates. The applied tensile load is of $1000 \mathrm{~N}$ on another free end as shown in Figure 7.

\section{Case 2: Optimum Angle}

For the case 2, analysis was done for optimum included angle on pattern of adhesion bonding. The included angle is the angle between the two adjacent faces of the notch shaped slots as shown in Figure 8.

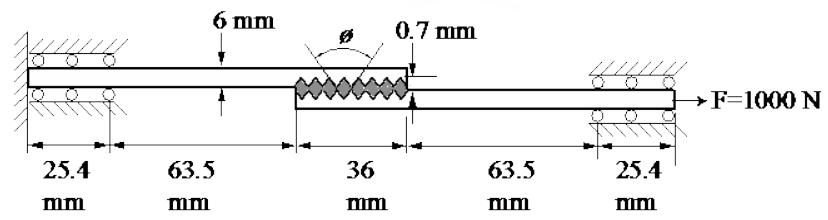

Figure 8. Optimum Angle for Single Lap Joint with notches

Boundary conditions for this case are as, fixed support on one end, frictionless support of $25.4 \mathrm{~mm}$ length on both ends of plate. The applied tensile load of $1000 \mathrm{~N}$ on the other free end

\subsection{FEA Procedure in Analysis}

The Analysis procedure begins with 3D CAD Modelling (PTC Creo) and FEA analysis with ANSYS Package.
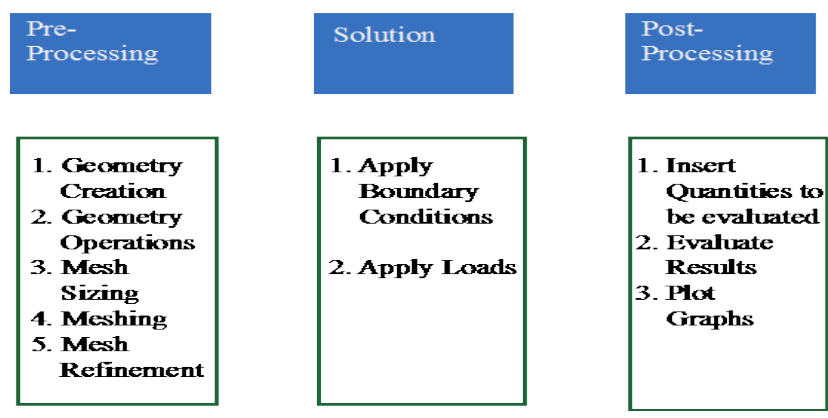

Figure 9. FEA procedure using ANSYS

The analysis procedure using ANSYS [13,14] is given in Figure 9. The FEA model of single lap joint without notches is given in Figure 10. It is used for further Analysis to find stress distribution in joint.

FEA analysis of adhesive joint gives some important observations as below,

- In this type of joint the highest stress concentrations occurs (at the free ends of the joint).

- The centre of the joint transfer less loads.

- Tapered or bevelled external scarf or radial fillets minimize the stress concentrations at the free ends of the joint.

- Unsupported single-lap joints used for thin metallic adherends. 
- Peel stresses in fibre-reinforced plastic adherends are very severe so it is not advised to use this geometry for structural applications with these materials.

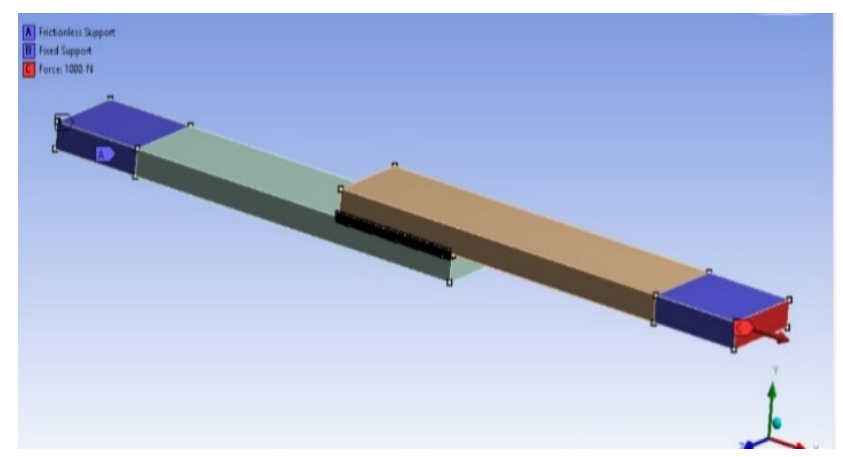

Figure 10. FEA Model of SLJ with Boundary Condition

\section{Testing of SLJ}

Two aluminum T6061 plates with epoxy resin were used to form a Single Lap Joint without notch. A single lap joint geometry samples are prepared for experimentation. The bonding surface area is cleaned with acetone before the application of the adhesive.Then bond surfaces cleaned to free from grease and dust particles. This is important since proper wetting of the adherend surface requires the surface to be clean. Any grease and dust might create tiny regions unbound regions which negatively affects the strength of the SLJ. Acetone is the preferred cleansing agent in this regard. Then, Activator applies on both surfaces of one adhered plate and adhesive on an adherend surface. The adhesive is applied on the adherend surface and spread over it with a spatula. The adherends are then bonded by applying constant pressure on the specimen up to $48 \mathrm{hrs}$. The joints were cured at room temperature for $48 \mathrm{hrs}$. The adhesive thickness is $0.35 \pm 0.05 \mathrm{~mm}[10]$. Then bonded plates clamped under the uniform fixture for bonding. Then adhesive joint specimens under goes testing on UTM (Specification: INSTRON 3345 , Capacity $5 \mathrm{KN}$, Vertical test space $1123 \mathrm{~mm}$, Loading rate $5 \mathrm{~mm} / \mathrm{min}$ ) as shown in Figure 11 [8].

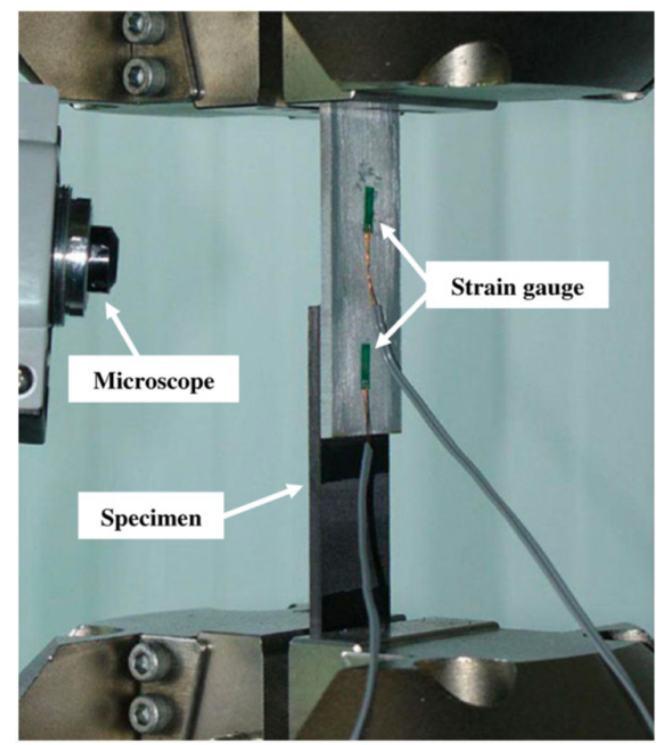

Figure 11. Experimental Setup for SLJ using UTM [8]

\section{Results}

The single lap joint undergoes two analysis phases, first without notches and second with notches on adhesion region. These are given as below,

\subsection{Case 1: SLJ without Notches}

In single lap joint without notch, first analysis was performed on different overlap lengths as $30 \mathrm{~mm}$ to $37 \mathrm{~mm}$. Result shows minimum stress was obtained for overlap length of $36 \mathrm{~mm}$. Thus, $36 \mathrm{~mm}$ is the optimum overlap length. The principle stress distribution for $36 \mathrm{~mm}$ overlap length is given in Figure 12.

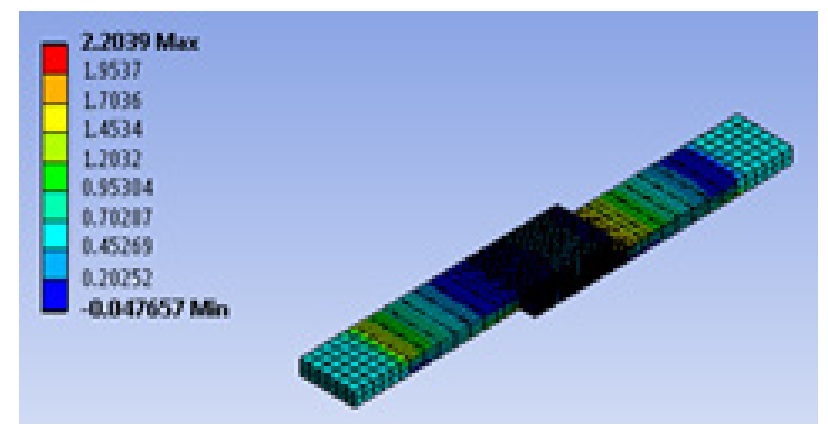

Figure 12. Maximum Principle Stress for SLJ without notches

Then the strength of the joint vs the overlap length was plotted as shown in Figure 13. It shows that the strength of the SLJ increases with increase in overlap length up to 36 $\mathrm{mm}$ for our setup. Thereafter it decreases with further increases in overlap length. Hence $36 \mathrm{~mm}$ is the optimum overlap length.

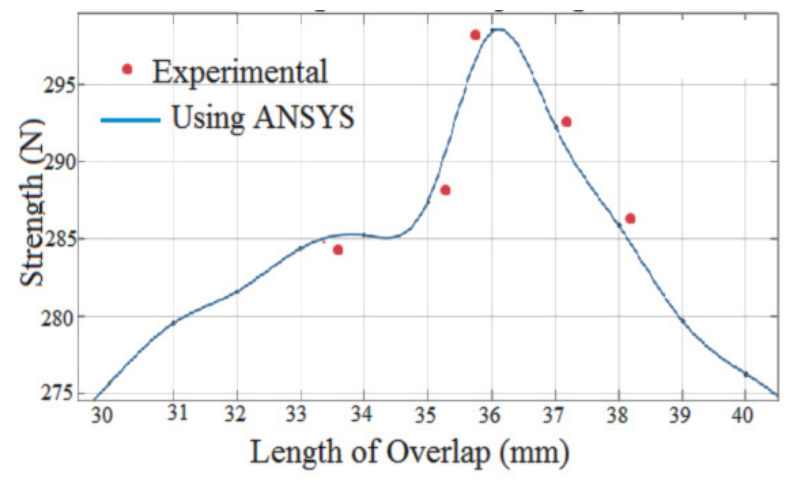

Figure 13. Strength vs. Overlap Length of SLJ (Without notch on adherend surface)

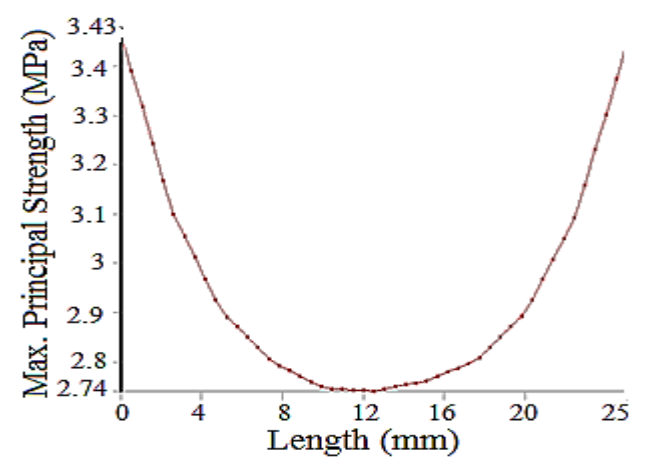

Figure 14. Variation of Maximum Principle Stress across width of the Single Lap Joint (Without notch on adherend surface) 
The FEA analysis given principle stress values for various bond length along the width of the specimen is plotted in Figure 14.

It observed that the principle stress value is maximum at the edges and minimum in the centre of SLJ.

\subsection{Case 2: SLJ with Notches}

In second case of SLJ with notches FEA analysis was done for different angles of triangular notches at angles varying from 0 to $180^{\circ}$. It was found that $75^{\circ}$ is the optimum angle where the bond strength will be maximum. The distribution of maximum principle stress for $75^{\circ}$ optimum notch angle is shown in Figure 15.

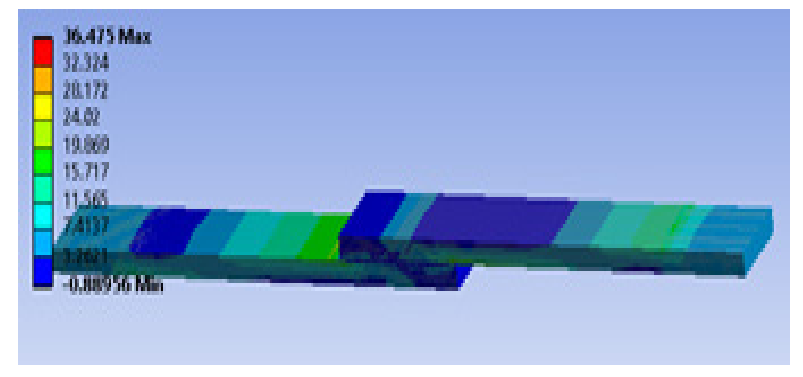

Figure 15. Principle stress for optimum angle of $75^{\circ}$ notches on the SLJ

FEA Analysis was used to find principle stress on various notch angles. The plot of strength of the SLJ with notches vs the notch angle is shown in Fig. 15. It shows that the strength of the SLJ with notches increases with increase in notch angle up to $60^{\circ}$, then it decreases up to $70^{\circ}$ but thereafter it increases with further increases in notch angle up to $75^{\circ}$ which seems to be the highest. Later on, it decreases continuously. Hence $75^{\circ}$ is the optimum notch angle. Although three peaks are seen in the graphs, the global maxima occur at $75^{\circ}$. Hence, that value was used as the final optimum value. The other two peaks, which are the local maxima provide and inferior strength, hence not used in further processes.

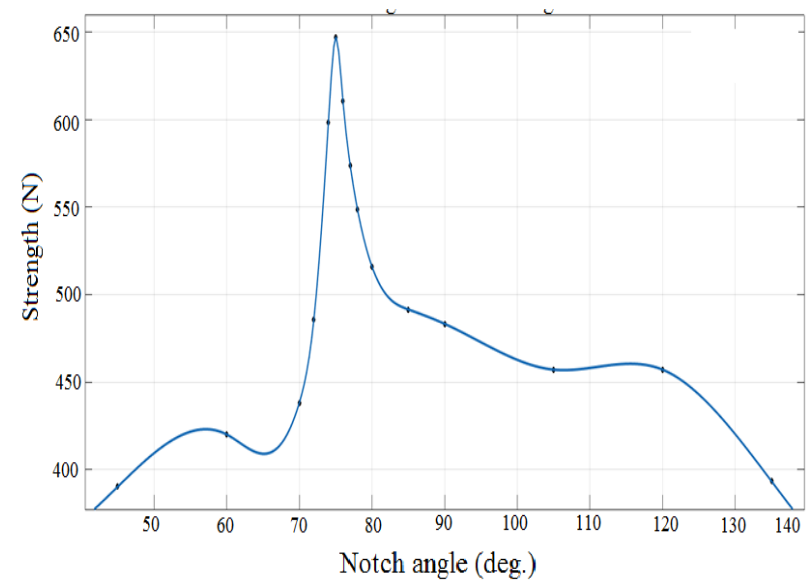

Figure 16. Strength vs. Included Angle (With notch on adherend surface)

The distribution of maximum principle stress across the width of the SLJ is shown in Figure 17.

It's observed that the maximum principle stress in the SLJ with notch occurs at the edges. The maximum principle stress is minimum at the centre of the SLJ with notches. This maximum principle stress distribution is similar to the SLJs without notches. The above two analysis gives optimum length $(l)=36 \mathrm{~mm}$ and optimum notch angle $75^{\circ}$. The optimized bond parameters are as depicted in the Figure 18.

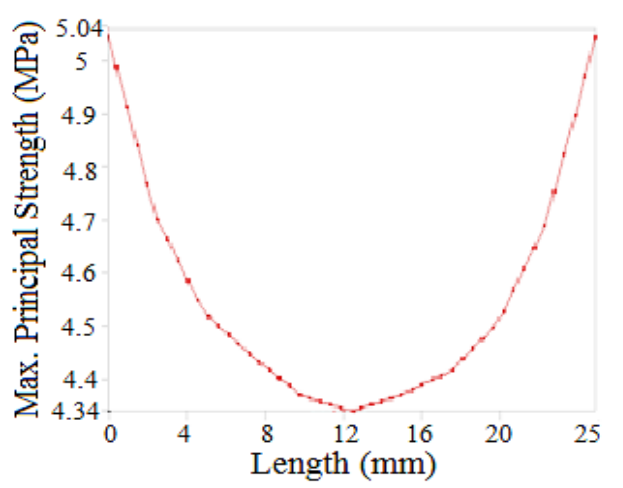

Figure 17. Variation of Shear Stress across width of SLJ (With notch on adherend surface)

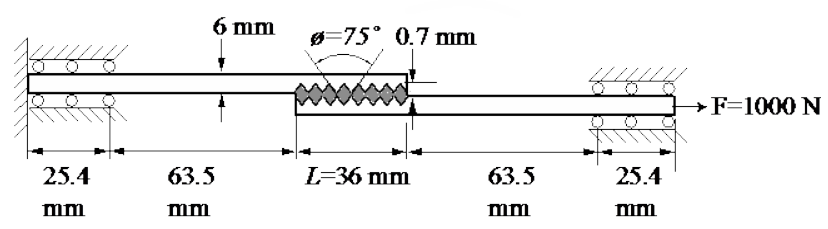

Figure 18. Variation of Shear Stress across Width of SLJ

FEA analysis and experimentation shown final results for single lap joining as, the optimum angle of notch on aluminium adherend plate is $75^{\circ}$ and optimum length of adhesive joining is $36 \mathrm{~mm}$ for single lap adhesive joint.

\section{Conclusion}

The study presented in this article single lap adhesively bonded joint configurations that are employed in various applications. The main outcomes of this study is to understand joining of two plate with varying surface roughness using adhesive joint and see failure analysis using FEA and experimental testing. Triangular notch were made on the surface of the plates. Maximum bond strength was obtained from optimum overlap length and triangular notch with obtained angle. The overlap length is most important factor which affects adhesive strength, joining procedure, adhesive and adherend properties. For the optimal overlap length gives maximum joint strength with minimum applied adhesive which also increases load bearing capacity of joint. The tensile strength of structural adhesive is obtained by loading the bonded adhesive plates on UTM. Thus, the strength of a single Lap Joint is the maximum when the length of overlap is $36 \mathrm{~mm}$ and the included angle of the notch is $75^{\circ}$ to achieve maximum strength of Single Lap Joint. In future, experimental validation of the results for SLJs with various notch angle will be performed.

\section{Acknowledgements}

We are grateful for all the support given by department of Mechanical Engineering, MIT College of Engineering, Pune. 


\section{Nomenclature}

$t \quad$ Thickness of plate (mm)

$l \quad$ Length of overlap (mm)

$s \quad$ Distance between two slots (mm)

E Young's modulus $\left(\mathrm{N} / \mathrm{mm}^{2}\right)$

$v \quad$ Poisson's ratio

$P \quad$ Pressure $\left(\mathrm{N} / \mathrm{mm}^{2}\right)$

$K \quad$ Bulk modulus $\left(\mathrm{N} / \mathrm{mm}^{2}\right)$

$G \quad$ Modulus of rigidity $\left(\mathrm{N} / \mathrm{mm}^{2}\right)$

$S_{y t} \quad$ Yield Tensile strength $\left(\mathrm{N} / \mathrm{mm}^{2}\right)$

$S_{y c} \quad$ Yield Compressive strength $\left(\mathrm{N} / \mathrm{mm}^{2}\right)$

$S_{u t} \quad$ Ultimate Tensile strength $\left(\mathrm{N} / \mathrm{mm}^{2}\right)$

$S_{u c} \quad$ Ultimate Compressive strength $\left(\mathrm{N} / \mathrm{mm}^{2}\right)$

\section{References}

[1] Nitinkumar Anekar, Sameer Shaikh, Pravin Kanase, Ajinkya Patil and Suraj Tarate, Single Lap Adhesive Joint (SLAJ): A Study. International Journal of Current Engineering and Technology, 2017.

[2] A. Ghumatkar, S. Budhe, R. Sekhar, M.D. Banea, S. de Barros, Influence of Adherend Surface Roughness on the Adhesive Bond Strength. Latin American Journal of Solids and Structures, 2016.

[3] Lucas da Silva, Effect of material, geometry, surface treatment and environment on Shear Strength of Single Lap Joints, 2009.
[4] Ab Ghani A. F., and Ahmad Rivai, Review on failure prediction techniques of composite single lap joint. AIP Conference Proceedings, 2016.

[5] Yasmina Boutar, Sami Naimi, Salah Mezlini, Moez Ben Sik Ali, Effect of surface treatment on the shear strength of aluminium adhesive single- lap joints for automotive applications. International Journal of Adhesion \& Adhesives, Elsevier, 2015.

[6] Venkateswara Rao, K. Mohan Rao, V. Rama Chandra Raju (2008), Analysis of Adhesively Bonded Single Lap Joint in Laminated FRP Composites Subjected to Transverse Load, India.

[7] Hazimeh (2014), finite element analysis of adhesively bonded composite joints subjected to impact loadings.

[8] Myeong-Su Seong, Tae-Hwan Kim, Khanh-Hung Nguyen, JinHwe Kweon, Jin-Ho Choi, A parametric study on the failure of bonded single-lap joints of carbon composite and Aluminium, 2008.

[9] Design and Testing of bonded and bolted Joints, National Physical Laboratory (UK), 2007.

[10] Huntsman Advanced Materials, "Araldite Standard: Two-component epoxy adhesive", October 2011.

[11] Standard Test Method for Apparent Shear Strength of Single-LapJoint Adhesively Bonded Metal Specimens by Tension Loading (Metal-to-Metal), ASTM D1005, 2013.

[12] J.L Clarke, EUROCOMP Design Code and Background Document, CRC Press, May 1996.

[13] Lucas da Silva, Analytical models of adhesively bonded jointsPart I: Literature survey, 2009.

[14] ANSYS Mechanical 19.2, Ansys Inc. 2018, available at: https://www.ansys.com.

[15] Creo v5, Parametric Technology Corporation, 2018, available at: https://www.ptc.com/en/products/cad/creo/.

(C) The Author(s) 2019. This article is an open access article distributed under the terms and conditions of the Creative Commons Attribution (CC BY) license (http://creativecommons.org/licenses/by/4.0/). 